\title{
Poverty trend among the lower class households in a rural area of Bangladesh
}

\author{
M. S. Kabir, F. R. Seamoon and M. A. Rahman ${ }^{1^{*}}$ \\ Department of Rural Sociology and ${ }^{1}$ Department of Agricultural Finance, Bangladesh Agricultural University, \\ Mymensingh-2202, Bangladesh, *E-mail: marahman2307@gmail.com
}

\begin{abstract}
The study undertakes to determine poverty trend among the lower class households during the last five years in a rural area of Bangladesh. A sample of size 80 lower class households was selected from two villages of Sherpur District in Bangladesh. The finding shows that the yearly average income and expenditure of the households were Tk 30912.50 and Tk. 25925, respectively. The change of the socioeconomic status of the lower class households has played an important role on changing pattern of poverty. Occupation of the respondent was significantly associated with change in poverty situation. A shift from lower level to higher level of a characteristic indicates, as a whole, the community has experienced a positive change in their livelihood. In statistical analysis, binary logistic regression model was fitted best. Among the occupation categories handicrafts seemed to help overcome the poverty situation more than business. Respondents involved in handicrafts were 3.673 times more likely to have a positive change in poverty situation compared to those involved in business. The result further suggests that respondents involved in agriculture were $96 \%$ significantly less likely to gain positive change than respondents involved in business and other activities. Findings of the study suggest that government should provide different types of facilities to rural lower class people and increase employment opportunities emphasizing more in handicrafts including handicrafts training.
\end{abstract}

Keywords: Poverty, Rural area, Bangladesh

\section{Introduction}

Bangladesh is a country of about 170 million people squeezed in an area of $1,47,570$ square kilometers with its population presently growing at the rate of $1.41 \%$ per annum, it is one of the densely populated developing countries in the world and predominantly a rural society, where $85 \%$ of its population draws their economic sustenance directly and indirectly from agriculture (BBS, 2009).

Poverty is a multi-dimensional concept. Poverty is usually defined as a situation in which a household or a person is unable to achieve a certain minimum level of welfare based on a priori yardstick. Traditionally, poverty is viewed as pronounced deprivation in well-being. "To be poor is to be hungry, to lack shelter and clothing, to be sick and not cared for, to be illiterate and not schooled" (World Bank, 2001) According to the broader definition, Poverty refers to forms of economic, social and psychological deprivation occurring among people lacking sufficient ownership control or access to resources to maintain or provide individual or collective minimum levels of living. In this view of the matter, poverty is a condition where families or individuals lack adequate access to or control of processes of resources accumulation and distribution (Hasnat, 1996).

The 2000 World Development Report on poverty broadens the notion of poverty to include vulnerability and exposure to risk. In Bangladesh most of the studies on poverty have focused mainly on income measures (Webb et al., 2002).

It is evident from Table 1 that the incidence of poverty is more in rural areas than in urban areas. Rural people are mostly affected and cannot overcome their poverty level.

Table 1. Poverty Head Count Rate (Upper poverty line)-2010

\begin{tabular}{|l|c|}
\hline Region & Percent of population below the poverty line \\
\hline Urban & 21.3 \\
Rural & 35.2 \\
National & 31.5 \\
\hline
\end{tabular}

Source: HIES, 2010 
According to the World Bank (World Bank, 2001), "poverty is pronounced deprivation in well-being", where well-being can be measured by an individual's possession of income, health, nutrition, education, assets, housing, and certain rights in a society such as freedom of speech. Also poverty is a lack of opportunities, powerlessness, and vulnerability. Poverty is truly a multidimensional phenomenon in such a setting and requires multi-dimensional policy and program interventions in order to improve the well-being of individuals and, hence, make them free from poverty. For example, economic growth is crucial to the creation of opportunities. However, growth is not enough; the poor and the vulnerable may not be able to benefit from growth, because they lack health, or skills, or access to basic infrastructure. Cultural and social distance and discrimination are other factors that may also at least partly exclude vulnerability to famine and disease, especially in the mountainous and remote areas of the sub-region (IFAD, 2001).

A high level of deprivation continues to plague South Asia, which, as Sub-Saharan Africa, is one of the regions with the lowest levels of social indicators. Despite the rapid improvements in infant mortality rate, life expectancy at birth and adult literacy, South Asia is still the second worst region with respect to social indicators, and it suffers from very low levels for the other human development indicators like the Human Development Index (HDI), the Gender Development Index (GDI) and the Gender Empowerment Index (GEM).

A major factor of rural poverty is landlessness and limited access to land. The extent of landlessness is very high in South Asian countries like India (22\%), and Bangladesh (49.6\%). Also, landlessness is increasing over time in these countries. In Bangladesh, for example, the percentage of landless households (defined as those with less than $0.2 \mathrm{ha}$ ) in total households was $46 \%$ in 1988 but $49.6 \%$ in 1995 , and their share of total land had declined by nearly half a percentage point (Anand and Ravallion, 1993).

Bangladesh is one of the world's poorest countries, ranking third after India and China in the extent of poverty. The population is predominantly rural, with about 85 per cent of its 178 million people living in rural areas. For their livelihoods rural people depend mainly on the land, which is both fertile and extremely vulnerable. Most of the country is made up of flood plain, and while the alluvial soil provides good arable land, large areas are at risk because of frequent floods and cyclones, which take lives and destroy crops, livestock and property.

The situation of poverty in rural Bangladesh has recently been receiving most of the attention. The high population growth, low level of economic activities particularly in rural areas may be identified as important causative factors for high incidence of rural poverty. Poverty is usually defined as a situation in which a household or a person is unable to achieve a certain minimum level of welfare based on an a priori yardstick. It is measured in Bangladesh as a minimum level of expenditure which can meet a person's basic needs, comprising food and nonfood items. According to the objectives, this study identified the changing pattern of poverty situation of lower class people in rural areas during the last five years. This study has provided valuable information to the social workers, policy makers and researchers for further study. It will also make some tentative policy recommendations which will in turn help to generate maximum benefit from the poverty trend.

Though several researchers attempted to study rural poverty, the researchers attempted to undertake the study with the following objectives;

(i) To show the changing pattern of poverty of the households during last five years.

(ii) To identify the determinants of change in poverty situation among the households.

\section{Materials and Methods}

Two villages namely Gazirkhamar and Pakuria of Sherpur sadar upazila were purposively selected. The survey method was applied in the present study because it was thought to have some advantages over other methods. Interviewing respondent's method was followed to achieve the objectives of this study. Considering the objectives, time and availability of fund and man- power, a sample size of 80 households was chosen randomly for the present study. The period of the present study was confined from January 
to June 2012. However, the data were collected from February to March 2012 through several visits. The interview schedule was used to collect necessary information. The selection of variables required a very careful consideration and comprehensive search. Therefore, as many as 15 characteristics of the lower class households were selected as the independent variables which were age, occupation, level of education, family size, children education, farm size, annual family income, information of saving, family planning awareness, housing, asset, sanitation, drinking water, access to health care facilities, membership of NGO and Government facilities.

A sample of size 80 was collected from sample population of the villages. Then primary data were collected from the sample respondents through direct interview by using semi-structured interview schedule. The collected data were then analyzed by using statistical tool, for example, Microsoft Excel and SPSS (Statistical Package for Social Science). Univariate analysis was used to find the frequency distribution of several variables. Some descriptive measures such as mean, standard deviation are calculated for height and weight. Chi-square test of independence is performed to test the existence of interrelationship among the categories of two qualitative variables. To compare the significant difference between two means and proportions, the relevant statistical tests are also utilized (Cogill, 2003).

This study used Cox's (1970) linear logistic regression model for multivariate analysis to determine the relative effects of each independent variable on poverty status.

\section{Single level binary logistic regression}

The form of the logistic regression model is

$P=p(Y=1 / X)=\frac{e^{\beta_{0}+\beta_{1} X}}{1+e^{\beta_{0}+\beta_{1} X}}$

and, $1-P=p(Y=0 / X)=\frac{1}{1+e^{\beta_{0}+\beta_{1} X}}$

Where, $X$ is the independent variable and

$\mathrm{Y}$ is the dependent variable

( $y=1$, if there is positive change, and $y=0$, otherwise)

Then a transformation of $P$ known as the logit transformation and is defined as

$g(x)=\log i t P=\log \left[\frac{P}{1-P}\right]=\beta_{0}+\beta_{1} X$

For more than one independent variable the model generalizes as

$g(x)=\operatorname{Logit}\left(P_{i}\right)=\beta_{0}+\sum_{I=1}^{\mathrm{k}} \beta X_{i}$

Change occurred among the rural lower class households during last five years were measured as the dependent variable of the study. Score assigned 1 and 0 to the responses of 'yes' and 'no' respectively.

\section{Results and Discussion}

The purpose of this section is to explore the relationship of the selected socioeconomic characteristics of the respondents with the change that has occurred during the last five years in their life. Change of the socioeconomic status of the lower class households has played an important role on changing pattern of poverty. Results of the Chi-square test between the selected socioeconomic characteristics of lower class households and the change of poverty situation are shown in the Table 2. 
Table 2. Change in poverty situation by socioeconomic and demographic characteristics

\begin{tabular}{|c|c|c|c|}
\hline \multirow[t]{2}{*}{ Characteristics } & \multirow[t]{2}{*}{$\mathbf{N}$} & \multicolumn{2}{|c|}{$\begin{array}{c}\text { Poverty Situation Changed } \\
\text { (\%) }\end{array}$} \\
\hline & & Yes & No \\
\hline \multicolumn{4}{|l|}{ Age $(p=0.590)$} \\
\hline $26-30$ & 17 & 52.9 & 47.1 \\
\hline $31-40$ & 32 & 43.8 & 56.2 \\
\hline $41-50$ & 20 & 40.0 & 60.0 \\
\hline$>51$ & 11 & 27.3 & 72.7 \\
\hline \multicolumn{4}{|l|}{$\operatorname{Sex}(p=0.701)$} \\
\hline Male & 74 & 41.9 & 58.1 \\
\hline Female & 6 & 50.0 & 50.0 \\
\hline \multicolumn{4}{|l|}{ Occupation $(p=0.0001)$} \\
\hline Agriculture & 26 & 3.8 & 96.2 \\
\hline Day labourer & 25 & 52.0 & 48.0 \\
\hline Handicraft & 19 & 78.9 & 21.1 \\
\hline Business & 10 & 50.0 & 50.0 \\
\hline \multicolumn{4}{|l|}{ Level of Education $(p=0.387)$} \\
\hline Illiterate & 46 & 34.8 & 65.2 \\
\hline Can sign Only & 24 & 50.0 & 50.0 \\
\hline Primary & 8 & 62.5 & 37.5 \\
\hline Secondary & 2 & 50.0 & 50.0 \\
\hline \multicolumn{4}{|l|}{ Family Size $(p=0.525)$} \\
\hline 3-4(small) & 11 & 54.5 & 45.5 \\
\hline 5-7(medium) & 51 & 43.1 & 56.9 \\
\hline$>7($ large $)$ & 18 & 33.3 & 66.7 \\
\hline \multicolumn{4}{|l|}{ Annual Family Income $(p=0.687)$} \\
\hline$<20000$ & 1 & 0.0 & 100.0 \\
\hline $20000-25000$ & 8 & 50.0 & 50.0 \\
\hline $26000-30000$ & 27 & 37.0 & 63.0 \\
\hline $31000-35000$ & 33 & 42.4 & 57.6 \\
\hline$>35000$ & 11 & 54.5 & 45.5 \\
\hline \multicolumn{4}{|c|}{ Annual Family Expenditure $(p=0.015)$} \\
\hline$<20000$ & 7 & 71.4 & 28.6 \\
\hline $20000-25000$ & 7 & 0.0 & 100.0 \\
\hline $26000-30000$ & 18 & 45.8 & 54.2 \\
\hline $31000-35000$ & 48 & 38.9 & 61.1 \\
\hline \multicolumn{4}{|l|}{ Information of Savings $(p=0.472)$} \\
\hline Government Organization & 5 & 60.0 & 40.0 \\
\hline Local NGO & 41 & 36.6 & 63.4 \\
\hline NGO & 34 & 47.1 & 52.9 \\
\hline \multicolumn{4}{|l|}{ Housing Pattern $(p=0.794)$} \\
\hline Mud floor with straw roof & 60 & 43.3 & 56.7 \\
\hline Mud floor with roof & 20 & 40.0 & 60.0 \\
\hline \multicolumn{4}{|l|}{ Family Asset $(p=0.059)$} \\
\hline Bi-cycle & 1 & 100.0 & 0.0 \\
\hline Wall clock & 3 & 33.3 & 66.7 \\
\hline Hurricane & 61 & 39.3 & 60.7 \\
\hline Sewing machine & 4 & 100.0 & 0.0 \\
\hline Mobile Phone & 11 & 36.4 & 63.6 \\
\hline \multicolumn{4}{|c|}{ Number of livestock and others $(p=0.098)$} \\
\hline Cow & 19 & 42.1 & 57.9 \\
\hline Goat & 8 & 37.5 & 62.5 \\
\hline Poultry & 46 & 37.0 & 63.0 \\
\hline Fisheries & 7 & 85.7 & 14.3 \\
\hline
\end{tabular}

Note: $P$ values are based on chi-square test. Source: Field Survey, 2012. 
From the Table 2, it is observed that age of the respondent is insignificantly associated with change in poverty situation. Poverty situation changes more at the age group of 26 to 30 years during the last five years. Sex of the respondent is insignificantly associated with change in poverty situation. Poverty situation changes more, i.e. $50 \%$ among female respondents in the study area. Occupation of the respondent is significantly associated with the change in poverty situation at $1 \%$ level of significance. From the respondent's perspective, poverty situation has changed during the last five years with varying magnitude for different occupation which was more in case of handicrafts. About $79 \%$ of the respondents involved in handicrafts making reported to achieve change in their poverty situation. On the other hand, most of the respondents engaged in agriculture had no change. Data from table 2 reveal that level of education is insignificantly associated with change in poverty situation. The people who read about primary level think that they overcome the poverty situation more than the illiterate people in the study area.

Family size of the respondent has no significant effect on change in poverty situation. Small Families in the study area (about 55\%) overcome their poverty situation more in last five years. About $55 \%$ of the respondents whose yearly income is more than TK.35000 reported to achieve change in their poverty situation. On the other hand, most of the respondents in lower income groups had no change. Yearly expenditure of the respondent is significantly associated with change in poverty situation at $5 \%$ level of significance. From the saving pattern we can see that poverty situation changed more among the respondents who save their extra earnings in government organization than in non government organization. Family asset of the respondent is significantly associated with change in poverty situation at $10 \%$ level of significance. All of the respondents having sewing machine and bi-cycle reported to achieve change in their poverty situation.

Number of livestock and others is significantly associated with change in poverty situation at $10 \%$ level of significance. About $86 \%$ of the respondents involved in fisheries reported to achieve change in their poverty situation. On the other hand, most of the respondents engaged in poultry had no change.

From the Table 3 , it is revealed that percentage of poverty situation has changed during last five years with changing socioeconomic characteristics. A shift of the percent distribution between 'before' to 'after' from lower level to higher level of a characteristic indicates as a whole the community has experienced a positive change in their livelihood. Percentage of poverty situation has changed during last five years with changing annual family income of the respondent. After five years the respondents have experienced a positive change from the lower level to upper level of family income. With changing the family asset from lower level to upper level, poverty situation changes during last five years. Since the communication technologies has been developed in rural areas, the respondents of the study area use mobile phone in recent days.

The respondents of the study area have experienced a positive change in case of contraceptive use. In case of income generating activities more percentage of the respondents have fisheries and cows currently which is more effective than poultries and goats in changing poverty situation (see Table 3 ).

From the Table 3, we can see that among the health care facilities the percentage change of village doctor facilities were more (from $38.8 \%$ to $48.8 \%$ ) than other facilities. None of the respondents used to go to the upazila (sub-district) health complex five years before, now some start to go. 
Table 3. Changing household characteristics during the last five years

\begin{tabular}{|c|c|c|}
\hline Characteristics & Before & After \\
\hline \multicolumn{3}{|l|}{ Family Size } \\
\hline Small(3-4) & 25.00 & 13.80 \\
\hline Medium(5-7) & 57.50 & 63.80 \\
\hline Large $(>7)$ & 17.50 & 22.50 \\
\hline \multicolumn{3}{|l|}{ Annual Family Income (TK.) } \\
\hline$<20000$ & 10.00 & 1.30 \\
\hline $20000-25000$ & 42.50 & 10.00 \\
\hline $26000-30000$ & 38.80 & 33.80 \\
\hline $31000-35000$ & 8.80 & 41.30 \\
\hline$>35000$ & 0.00 & 13.80 \\
\hline \multicolumn{3}{|l|}{ Annual Expenditure (TK.) } \\
\hline$<20000$ & 26.30 & 8.80 \\
\hline $20000-25000$ & 51.30 & 8.80 \\
\hline $26000-30000$ & 20.00 & 60.00 \\
\hline $31000-35000$ & 2.50 & 22.50 \\
\hline \multicolumn{3}{|l|}{ Information of Saving } \\
\hline Government Organization & 7.50 & 6.30 \\
\hline Local NGO & 46.30 & 51.30 \\
\hline NGO & 46.30 & 42.50 \\
\hline \multicolumn{3}{|l|}{ Housing } \\
\hline $\begin{array}{l}\text { Mud Floor With Straw Roof } \\
\text { Mud Floor With Straw Roof } \\
\text { Family Asset }\end{array}$ & $\begin{array}{l}86.30 \\
13.80\end{array}$ & $\begin{array}{l}75.00 \\
25.00\end{array}$ \\
\hline Bi-cycle & 1.30 & 1.30 \\
\hline Radio & 7.50 & 3.80 \\
\hline Hurricane & 91.30 & 76.30 \\
\hline Sewing machine & 0.00 & 5.00 \\
\hline Mobile phone & 0.00 & 13.80 \\
\hline \multicolumn{3}{|l|}{ Number of Livestock and Others } \\
\hline Cow & 2.50 & 23.80 \\
\hline Goat & 15.00 & 10.00 \\
\hline Poultry & 77.50 & 57.50 \\
\hline Fisheries & 5.00 & 8.80 \\
\hline \multicolumn{3}{|l|}{ Sanitation } \\
\hline Open places & 32.50 & 8.80 \\
\hline Katcha latrine & 67.50 & 76.30 \\
\hline Pucca latrine & 0.00 & 15.00 \\
\hline \multicolumn{3}{|l|}{ Health Facilities } \\
\hline Upazila health complex & 0.00 & 2.50 \\
\hline Community clinic & 3.80 & 12.50 \\
\hline Village doctor & 38.80 & 48.80 \\
\hline Homeopathic & 6.30 & 6.30 \\
\hline Kabiraj & 51.30 & 30.00 \\
\hline \multicolumn{3}{|l|}{ Contraceptive Use } \\
\hline Yes & 32.50 & 53.8 \\
\hline No & 67.50 & 46.2 \\
\hline
\end{tabular}

Source: Field Survey, 2012 


\section{Binary logistic regression model}

Among the variables considered in regression analysis only occupation had a significant effect on the change in poverty situation.

Age of the respondent has a negative effect on the change of poverty situation. The regression analysis shows that male respondents were 3.19 times more likely to experience a change in the poverty situation than a female respondent.

Education had a positive effect on the change of poverty situation. Table 4 shows that if a respondent has education of at least primary level, he (she) is 2.66 times more likely to report a positive change in poverty situation than an uneducated respondent.

Among the occupation categories handicrafts seemed to help overcome the poverty situation more than business. Respondents involved in handicrafts are 3.673 times more likely to have a positive change in poverty situation compared to those involved in business.

Table 4. Binary logistic regression results indicating the effects of different socio-economic variables on the change in poverty situation

\begin{tabular}{|l|c|c|c|}
\hline Dependent variables & B & S.E. & Odds Ratio \\
\hline & & & \\
\hline Age of the respondent & -0.008 & 0.048 & 0.992 \\
\hline Sex (reference: female) & & & \\
\hline & 1.161 & 1.042 & 3.194 \\
\hline Occupation (reference: business and others) & & & \\
\hline$\quad$ Agriculture & & & \\
\hline Day labourer & $-3.488^{*}$ & 1.251 & 0.031 \\
\hline Handicraft & -0.202 & 0.907 & 0.817 \\
\hline & 1.301 & 0.914 & 3.673 \\
\hline Education of the respondent (reference: uneducated) & & & \\
\hline Primary and above & & & \\
\hline & 0.979 & 0.977 & 2.661 \\
\hline Constant & & & \\
\hline
\end{tabular}

Note: * indicates significant at 1\%. Source: Field Survey, 2012

\section{Conclusion}

The incidence of poverty in Bangladesh is higher than in any other south Asian countries. The poverty situation in Bangladesh has become grave because of an income distribution pattern following a dynamics that continue to favor relatively the richer section of the population. Poverty consists in the lack of certain basic capabilities of the human beings. The capabilities to live a healthy active life, free of avoidable morbidity and premature mortality, live with dignity with adequate clothing and shelter etc.

Though Bangladesh is an agro-based country and most of the populations in rural areas are engaged in agriculture, the result of the study presents that handicraft and business are more helpful in increasing their income to alleviate poverty than agriculture. For this reason, if we can train our lower class households making handicrafts in rural areas specially the younger groups, we can overcome our present poverty situation in future days. 
The present study was conducted in only two villages and investigated the relationship between the selected socioeconomic characteristics and the poverty situation changed during last five years. Therefore it is recommended that similar research effort be carried out in different rural areas of Bangladesh covering more characteristics of the rural lower class households. In view of the above considerations, the following strategies are recommended:

i) The status of rural lower class households could be improved via a number of approaches, with access to formal education being a foremost concern. The provision of community-based education to rural lower class households is something which, if supported by government organizations, NGOs and local community leaders would be effective in beginning to uproot illiteracy and related social deficiencies from rural communities. Likewise, addressing social and cultural education should be ensured.

ii) Encouraging lower class in rural areas would be a step toward increasing their empowerment since this would facilitate greater mobility outside the home and their access to media. Local community leaders, extension personnel, NGO workers would provide a vital contribution to such group by motivating them toward engaging in various development activities.

iii) Effort should be made to promote rural women's participation in decision-making, including through affirmative action, and to provide support for women's organizations, labour unions or other associations and civil society groups that promote rural women's rights.

\section{References}

Anand, S. and Ravallion, M. 1993. Human Development in Poor countries on the role of private income and public services, journal of economic perspectives. Vol. 7, No.1, page 133-150.

BBS 2009. Statistical Yearbook of Bangladesh, Bangladesh Bureau of Statistics, Statistics Division, Ministry of Planning, Government of the People's Republic of Bangladesh, Dhaka. Page,33.

Cogill, B. 2003. Anthropometric Indicators Measurement Guide. Page, 1-93

Cox, D.R. 1970. The Analysis of Binary Data. Methuen, London.Page.17

Hasnat, A. 1996. Below the Line-“Rural Poverty in Bangladesh”. Dhaka University Press Ltd.Page, 1-277.

Hossain, M. and Sen, B. 1992. Rural Poverty in Bangladesh. Trends and determinates. Asian Development Review. Vol.10,No.1, page, $1-34$.

HIES 2010. Household Income and Expenditure Survey. Statistical Yearbook of Bangladesh, Bangladesh Bureau of Statistics, Statistics Division, Ministry of Planning, Government of the People's Republic of Bangladesh, Dhaka. Page, xxv.

IFAD 2001. Enabling the Rural Poor to Overcome Poverty in Bangladesh. International Fund for Agricultural Development. Rome, Italy.Page, 370-386.

Webb, P., Coates, J. and Houser, R. 2002. Allocative Responses to Scarcity: Self Reported Assessments of Hunger Compared with Conventional Measures of Poverty and Malnutrition in Bangladesh. Food Policy and Applied Nutrition Program, Discussion paper No. 13, TUFTS Nutrition <http : // nutrition. tufts. edu / pdf/ publications/ fpan/ wp 13-allocative _ responses. pdf>

World Bank. 2001. World Development Report 2000-01. Oxford University Press. Page, 1-352. 